\title{
Videodensitometric quantification of paravalvular regurgitation of a transcatheter aortic valve: in vitro validation
}

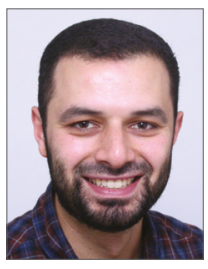

\author{
Mohammad Abdelghani' ${ }^{1}, \mathrm{MD}, \mathrm{MSc}$; Yosuke Miyazaki², MD, PhD; Ellen S. de Boer ${ }^{3}$, BSc; \\ Jean-Paul Aben ${ }^{4}$, BSc; Math van Sloun ${ }^{5}$, BSc; Todd Suchecki', BSc; Marcel van 't Veer', PhD; \\ Osama Soliman ${ }^{2,7}, \mathrm{MD}, \mathrm{PhD}$; Yoshinobu Onuma ${ }^{2,7}, \mathrm{MD}, \mathrm{PhD}$; Robbert de Winter ${ }^{1}, \mathrm{MD}, \mathrm{PhD}$; \\ Pim A.L. Tonino 6 , MD, PhD; Frans N. van de Vosse ${ }^{3}$, PhD; Marcel C.M. Rutten ${ }^{3}, \mathrm{PhD}$; \\ Patrick W. Serruys ${ }^{8 *}, \mathrm{MD}, \mathrm{PhD}$
}

1. Department of Cardiology, Academic Medical Center, University of Amsterdam, Amsterdam, the Netherlands; 2. Erasmus University Medical Center, Rotterdam, the Netherlands; 3. Department of Biomedical Engineering, Eindhoven University of Technology, Eindhoven, the Netherlands; 4. Pie Medical Imaging, Maastricht, the Netherlands; 5. ACIST Medical Systems, Eden Prairie, MN, USA; 6. Catharina Hospital, Eindhoven, the Netherlands; 7. Cardialysis Clinical Trials Management and Core Laboratories, Rotterdam, the Netherlands; 8. International Centre for Circulatory Health, NHLI, Imperial College London, London, United Kingdom

M. Abdelghani and Y. Miyazaki contributed equally to this manuscript.

GUEST EDITOR: William Wijns, MD, PhD; Lambe Institute for Translational Medicine and Curam, National University of Ireland, Galway, and Saolta University Healthcare Group, Galway, Ireland; Cardiovascular Research Center Aalst, Belgium

This paper also includes supplementary data published online at: http://www:pcronline.com/eurointervention/128th_issue/246

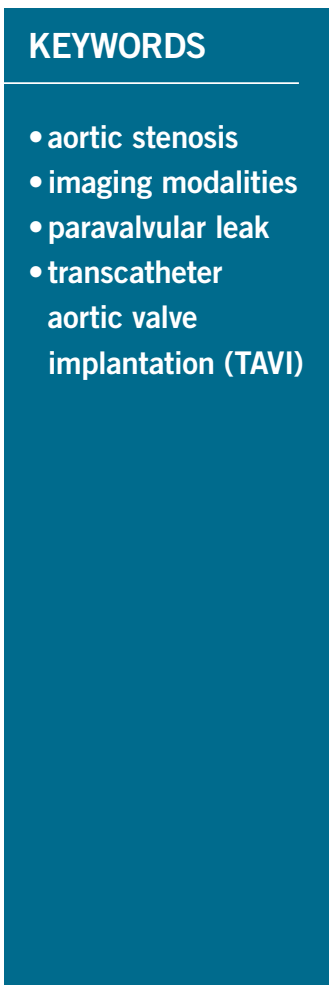

\section{Abstract}

Aims: Videodensitometric assessment of aortography provides a periprocedural quantitation of prosthetic valve regurgitation (PVR) after transcatheter aortic valve implantation. We sought to compare the videodensitometric parameters of PVR severity to the regurgitation fraction (RF) in a controlled in vitro setting.

Methods and results: In a mock circulation system, a transcatheter balloon-expandable valve inserted at the aortic valve position was gradually deformed to induce different grades of paravalvular leakage and the RF was measured with a transonic flow probe. Contrast aortography was performed and the following videodensitometric parameters were generated: left ventricle aortic regurgitation (LV-AR), LV outflow tract AR (LVOT-AR), quantitative regurgitation assessment (qRA) index, relative maximum density (relative max), and maximum upslope of the LV time-density curve. The correlation was substantial between videodensitometric parameters (LV-AR, LVOT-AR, qRA index, relative max, and maximum upslope) and $\mathrm{RF}\left(r^{2}=0.96,0.96,0.93,0.87\right.$, and $0.93 ; \mathrm{p}<0.001$ for all). LV-AR (region of interest $[\mathrm{ROI}]=$ entire LV) and LVOT-AR (ROI=LVOT) were not different $(\mathrm{p}=0.51)$ and were strongly correlated $\left(r^{2}=0.99\right)$ with a mean difference of $1.92 \%$ (95\% limits of agreement: \pm 2.83$)$. The correlations of LV-AR and LVOT-AR with RF were stronger when more than one cardiac cycle was included in the analysis (one cycle: $r^{2}=0.85$ and $r^{2}=0.83$; four cycles: $r^{2}=0.96$ and $r^{2}=0.96$, for LV-AR and LVOT-AR, respectively). Including more cycles beyond four did not improve accuracy.

Conclusions: Quantitative assessment of PVR by videodensitometry of aortograms strongly correlates with the actual RF in a controlled in vitro setting. Accuracy is improved by including more than one cardiac cycle in the analysis.

\footnotetext{
*Corresponding author: Cardiovascular Science Division of the NHLI within Imperial College of Science, Technology and Medicine, South Kensington Campus, London, SW7 2AZ, United Kingdom.E-mail: patrick.w.j.c.serruys@pwserruys.com
} 


\section{Abbreviations}

AR

aortic regurgitation

LVOT

left ventricular outflow tract

PVR prosthetic valve regurgitation

qRA quantitative regurgitation assessment

RAUC relative area under the curve

RF regurgitation fraction

ROI region of interest

TAVI transcatheter aortic valve implantation

TDC time-density curve

THV transcatheter heart valve

TTE transthoracic echocardiography

\section{Introduction}

Since prosthetic valve regurgitation (PVR) after transcatheter aortic valve implantation (TAVI) is related to mortality ${ }^{1-3}$, accurate assessment of its severity is needed during the procedure when there is still a chance to avert it. Quantification of PVR, typically and most commonly paravalvular, is challenging ${ }^{4}$. Transoesophageal echocardiography (TEE) and aortography are the standard tools for the assessment of PVR during the procedure. However, echocardiography has a low reproducibility ${ }^{5}$ and a low sensitivity to detect paravalvular leaks in certain sectors of the device circumference ${ }^{6}$, and the Sellers method $^{7}$ of aortographic assessment is qualitative and subjective ${ }^{4}$.

Quantitative aortographic assessment of PVR after TAVI by videodensitometry is reported to overcome the limitations of the Sellers method ${ }^{4,8,9}$. In the first application of this technique to TAVI patients by Schultz et $\mathrm{al}^{10}$, the entire left ventricle (LV) was considered the region of interest (ROI) and the contrast density in the LV was compared to that in the aortic root to yield the quantitative regurgitation analysis (qRA) index. However, this method of analysis was not feasible in the majority of cases due to the influence of background structures overlapping the ROI (e.g., the contrast-filled descending aorta). In order to avoid this shortcoming, our group developed a modified method that restricts the analysis to the left ventricular outflow tract.

In the minimalist TAVI approach, which is becoming the default TAVI approach ${ }^{11,12}$, since general anaesthesia is replaced by sedation and TEE is seldom an option, quantitative aortographic assessment can serve as the first screening technique to determine the severity of PVR during the procedure. However, this technology is yet to be validated. In a mock circulation system, an artificial PVR was created in a balloon-expandable transcatheter heart valve (THV) and the videodensitometric aortographic assessment was compared to the actual regurgitation fraction measured by a transonic probe.

\section{Methods \\ THE MOCK CIRCULATION SYSTEM}

The mock circulation system, shown in Figure 1, consists of three components: 1) an elastic silicone tube corresponding to the aortic root, 2) a THV module (a $25 \mathrm{~mm}$ diameter plastic tube in which a THV was deployed), and 3) a rigid polycarbonate tube including a servomotor-operated piston pump acting as the $\mathrm{LV}^{13,14}$. The system was submerged in a 30 litre water bath heated to 37 degrees Celsius. A pulsatile cardiac output of $5 \mathrm{~L} / \mathrm{min}$ was generated at a rate of 75 cycles/min with a corresponding ISO 5840-compliant flow curve ( $35 \%$ systole and $65 \%$ diastole per cycle).

\section{THE PVR MODEL}

To mimic the asymmetric underexpansion of a THV by a calcium chunk in the landing zone, a radiolucent screw was inserted radially into the THV module and pushed to deform the stent of a $26 \mathrm{~mm}$ SAPIEN XT device (Edwards Lifesciences, Irvine,

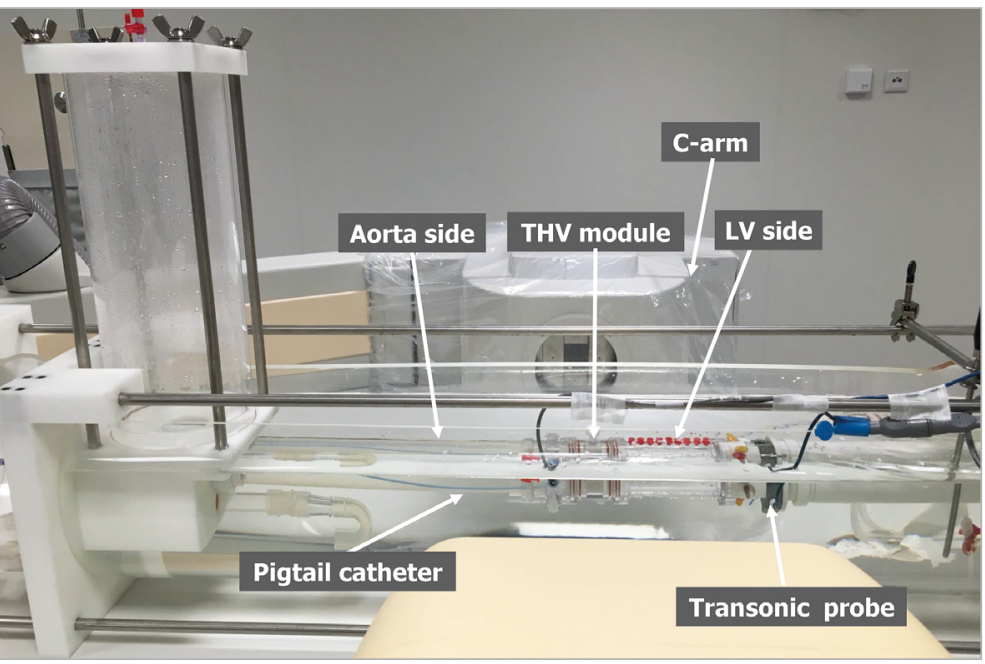

Figure 1. The mock circulation system. The mock circulation system was set in the cathlab with a C-arm angulation of LAO 90/CRA 0. The system consists of: 1) aorta side: an elastic tube corresponding to the aortic root seen on the left-hand side of the Figure, 2) transcatheter heart valve (THV) module: a balloon-expandable THV within a plastic tube seen in the middle, and 3) left ventricle (LV) side: a tube including a servomotor-operated piston pump seen on the right-hand side of the Figure. 
CA, USA) from the outside (Figure 2). The screw was advanced gradually to create an increasing amount of paravalvular leakage. The device used was clinically discarded and transvalvular regurgitation (regurgitation fraction: 12\%) (Figure 3) was present at baseline before creating paravalvular leakage. The flow rate was measured with a transonic flow probe (Transonic 28 PAU, with TS 410 flowmeter; Transonic Systems Inc., Ithaca, NY, USA) positioned between the outlet of the pump and the aortic valve. The regurgitation volume for each heart beat was calculated as the difference between forward stroke volume and reverse flow volume. The regurgitation fraction (RF) was calculated by dividing the regurgitation volume by the forward stroke volume\% (Figure 3). The aortic valve closing volume ${ }^{15,16}$ was taken into account as a component of the reverse flow that does not represent an actual regurgitant flow (i.e., subtracted from the reverse flow).

\section{CONTRAST AORTOGRAPHY}

Fluoroscopic images were acquired in the cathlab (Catharina Hospital, Eindhoven, the Netherlands) at a C-arm angulation of LAO 90/CRA 0 (Figure 1). Contrast was injected through a $6 \mathrm{Fr}$ pigtail catheter whose tip was located $2 \mathrm{~cm}$ above the upper edge of the THV stent. The distance between the catheter tip and the THV stent edge was confirmed by offline measurement using a quantitative angiographic software (CAAS 5.11; Pie Medical Imaging, Maastricht, the Netherlands).

Contrast (Isovue-370; Bracco Diagnostics Inc., Monroe Township, NJ, USA) injection was performed using the ACIST $\mathrm{CVi}^{\circledR}$ contrast delivery system (ACIST Medical Systems, Eden Prairie, MN, USA). The set volume, rate, and pressure limit of contrast injection were $20 \mathrm{~mL}, 22.5 \mathrm{~mL} / \mathrm{s}$, and $700 \mathrm{psi}$, respectively. The mock circulation was heated to body temperature, to bring contrast solubility to physiological levels.

\section{QUANTITATIVE VIDEODENSITOMETRIC ANALYSIS OF CONTRAST AORTOGRAPHY}

A dedicated videodensitometry software (CAAS A-valve 2.0.2; Pie Medical Imaging) ${ }^{8-10}$ was used to analyse the contrast aortograms. For descriptive purposes, the three segments of the mock circulation system were labelled as "aortic root", "THV module" and "LV" (Figure 1). Contrast density in the "aortic root" served as a reference, to which the density in the ROI (the entire LV [LV$\mathrm{AR}$ ] or the basal third of the LV [LVOT-AR]) was compared (Figure 4A, Figure 4B, Moving image 1). The moment of contrast injection was indicated so that all static background radiodensities were subtracted from any further analysis. Using a semi-automatic algorithm, contrast time-density curves (TDC) were generated for the reference region (the aortic root) and for the ROI. The area under the curve (AUC) was automatically calculated as the time-density integral and the relative area under the curve (RAUC) was calculated as the AUC of the ROI divided by the AUC of the reference region\% (theoretical range: 0 to $100 \%$ ). In addition to the RAUC for the entire LV and for the LVOT, the quantitative regurgitation analysis (qRA) index was also calculated. In a qRA algorithm, not only the density and the duration of opacification of the LV, but also increasing apical depth of the leaking contrast are considered as markers of PVR severity (Figure 4C). The qRA index, which reproduces the concept of the Sellers method $^{7}$ (appreciating density, duration, and depth of LV opacification), yields a continuous severity scale ranging from 0 (indicating no contrast leakage into the LV) to 4 (indicating contrast filling of the entire LV with a greater density than the aortic root). From the cardiac cycle that shows the maximum contrast density value in the reference region, two other parameters were automatically calculated - the relative max (= the maximum time-density value of the ROI divided by the reference maximum time-density

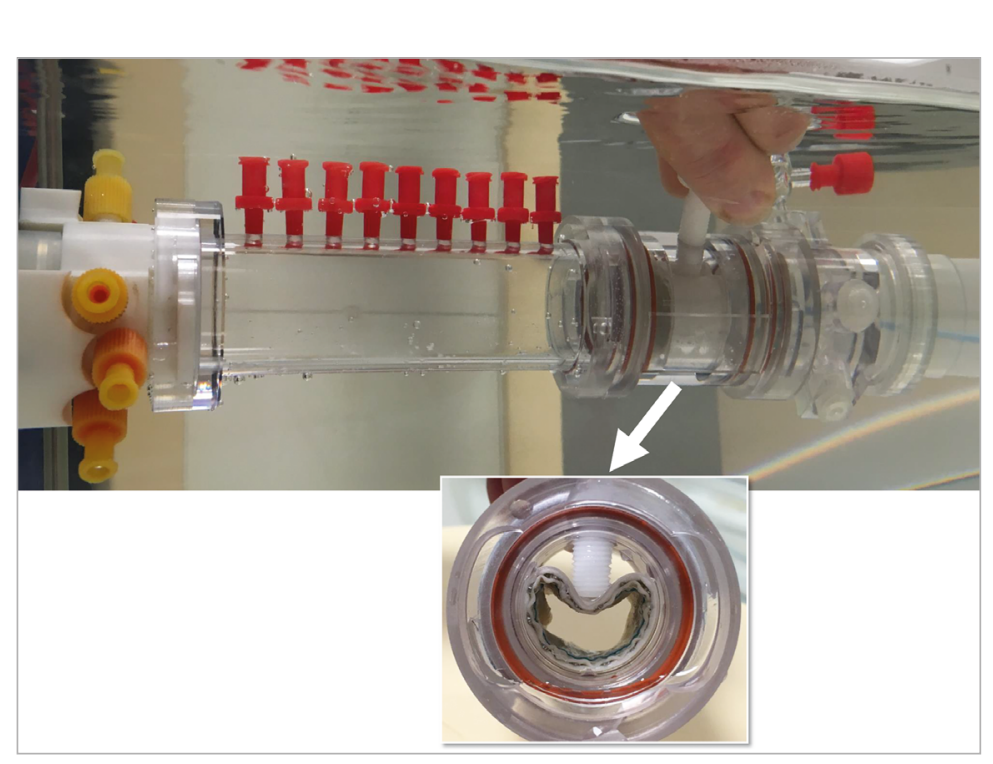

Figure 2. Paraprosthetic valve regurgitation model. The radiolucent screw was gradually advanced to create a controlled deformation of the prosthetic valve stent, producing increasing paravalvular leakage. The extent of device deformation depicted in this Figure was the maximum deformation (yielding a regurgitation fraction of $65 \%$ ). 


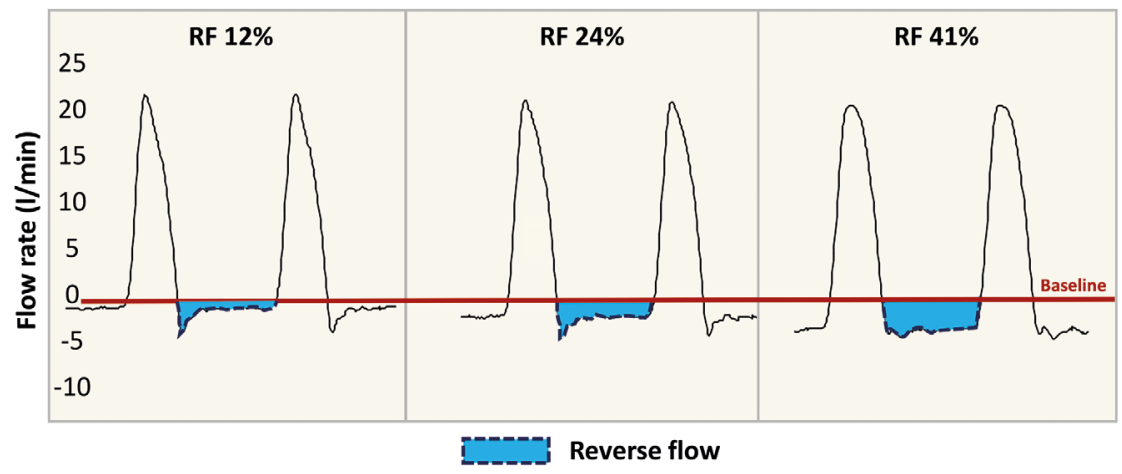

Figure 3. Flow rate curves generated from the readings of a transonic probe. Prosthetic valve regurgitation fraction (RF) was calculated as the regurgitation volume (below the baseline, blue tracing) excluding the closing volume divided by the forward stroke volume (above the baseline). Please note that the lowest $R F$ was $12 \%$ because a transvalvular regurgitation existed before deforming the valve stent.

value \%) and the maximum upslope (= the maximal slope during upstroke of the time-density curve of the ROI) (Figure 4).

\section{STATISTICAL ANALYSIS}

For numerical variables, when non-parametric statistical methods were used, we summarised data as median and interquartile range (IQR). Otherwise, numerical data were summarised as mean \pm standard deviation (SD). The relationship between continuous parameters of PVR severity was tested using Spearman's correlation. The sample size for correlation was estimated to be at least 10 data pairs (for an $\alpha$-level of 0.05 , a $\beta$-level of 0.20 [power $=80 \%$ ], and a hypothesised correlation coefficient $r=0.80$ [denoting a strong

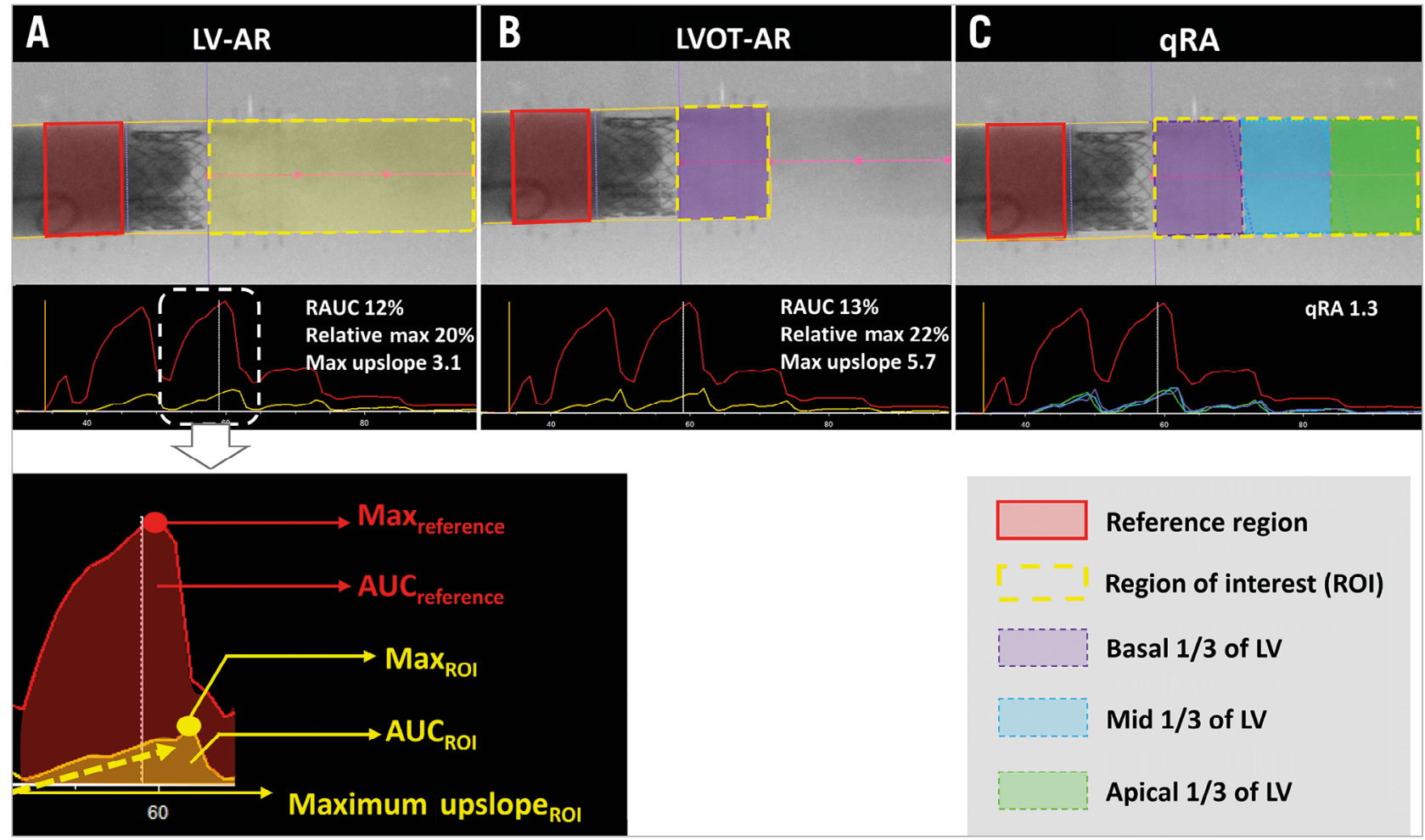

Figure 4. Videodensitometry parameters ( $L V-A R, L V O T-A R, q R A$, relative max, and maximum upslope). Representative figures for the assessment of LV-AR (A), LVOT-AR (B) and qRA index (C) are shown. Contrast density in the aortic root served as the reference density (red rectangle), to which the density in the region of interest (ROI; enclosed by the yellow dotted line) is compared. The ROI can be the entire left ventricle ( $L V-A R)$, the basal third of the LV (LVOT-AR) or the entire LV applying the quantitative regurgitation analysis ( $q R A)$ index concept. In the qRA algorithm $(C)$, three time-density curves are generated for the three segments of the LV (basal [violet], mid [blue], and apical [green]). The time-density values for the apical segment are more heavily weighted than the mid and basal, and the values for the mid segment are more heavily weighted than the basal segment. AUC: area under the time-density curve; RAUC: relative AUC 
correlation]). The reproducibility of videodensitometric assessment was assessed by calculating the intraclass correlation coefficient (ICC) presented with its $95 \%$ confidence interval (CI), and the difference between paired observations (bias) was displayed using the Bland-Altman method. The 95\% limits of agreement (95\% LOA) were estimated as $\pm 1.96 \times \mathrm{SD}$ of the bias. The Wilcoxon signed-rank test was performed to compare LV-AR and LVOT-AR.

\section{Results}

Twelve in vitro experiments were performed at different degrees of RF (mean \pm SD: $35.6 \pm 21.5 \%$; range: $11.8 \%$ to $65.3 \%$ ). The actual contrast injection volume and rate were (median [IQR]) 19.4 [19.2-19.9] $\mathrm{ml}$ and 21.1 [20.8-21.9] $\mathrm{ml} / \mathrm{sec}$.

\section{VIDEODENSITOMETRIC PARAMETERS VS. RF OF PVR}

The mean \pm SD (range) for videodensitometric parameters were as follows: LV-AR, 24.1 $18.3 \%$ (3.0-49.0\%); LVOT-AR, 26.0 $\pm 17.7 \%$ (6.0$50.0 \%)$; qRA index, $1.71 \pm 0.79(0.70-2.60)$; relative max, $30.8 \pm 23.9 \%$ (5.0-63.0\%); and maximum upslope, $6.73 \pm 6.29$ (0.80-16.30).

The correlation was substantial between LV-AR and RF ( $r^{2}=0.958, \mathrm{y}=0.845 \mathrm{x}-6.011$ ) (Figure 5A), between LVOT-AR and $\mathrm{RF}\left(r^{2}=0.964, \mathrm{y}=0.816 \mathrm{x}-3.049\right)$ (Figure 5B), between qRA index and RF $\left(r^{2}=0.933, \mathrm{y}=0.036 \mathrm{x}+0.417\right)$ (Figure $\left.5 \mathrm{C}\right)$, between relative max and RF $\left(r^{2}=0.874, \mathrm{y}=1.094 \mathrm{x}-8.130\right)$ (Figure 5D), and between maximum upslope and RF $\left(r^{2}=0.931, \mathrm{y}=0.286 \mathrm{x}-3.462\right)$

(Figure 5E), $\mathrm{p}<0.001$ for all.

LV-AR and LVOT-AR were not different $(\mathrm{p}=0.514)$ and were strongly correlated $\left(r^{2}=0.992, \mathrm{p}<0.001, \mathrm{y}=0.967 \mathrm{x}+2.718\right)$. The mean difference between LVOT-AR and LV-AR was 1.917\% (95\% LOA: \pm 2.828$)$.

\section{HOW MANY CARDIAC CYCLES TO INCLUDE IN VIDEODENSITOMETRIC ANALYSIS}

As shown in Figure 6, the correlations of LV-AR and LVOT-AR with RF were stronger when more than one cardiac cycle was used for the analysis. The correlation coefficient increased stepwise with the increasing number of cardiac cycles included, from one cycle (LV-AR: $r^{2}=0.854$, LVOT-AR: $r^{2}=0.830$ ) to four cycles (LV-AR: $r^{2}=0.962$, LVOT-AR: $r^{2}=0.962$ ). Including more cycles beyond four did not seem to add any meaningful accuracy to the analysis.

\section{REPRODUCIBILITY OF VIDEODENSITOMETRIC PARAMETERS}

To investigate the inherent variability of the method, videodensitometric assessment was repeated for each RF level by the same
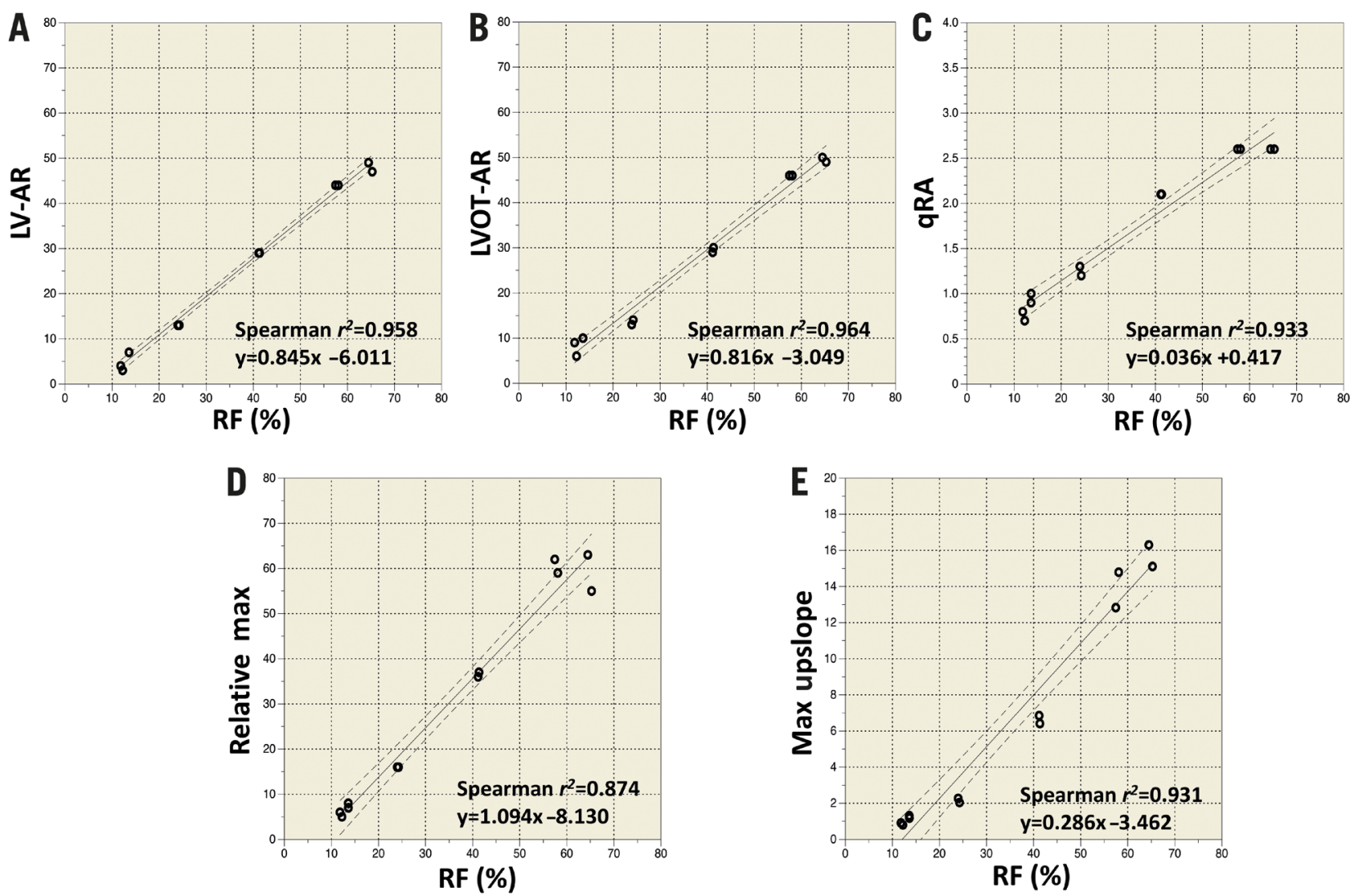

Figure 5. Correlation between videodensitometric parameters of PVR severity and RF. Scatter plots with the line of best fit and the $95 \%$ confidence interval lines displaying the relation between the regurgitation fraction ( $R F$; on the horizontal axis) and videodensitometric parameters of regurgitation severity on the vertical axis: $L V-A R(A), L V O T-A R(B), q R A$ index $(C)$, relative maximum (D), and maximum upslope (E). 

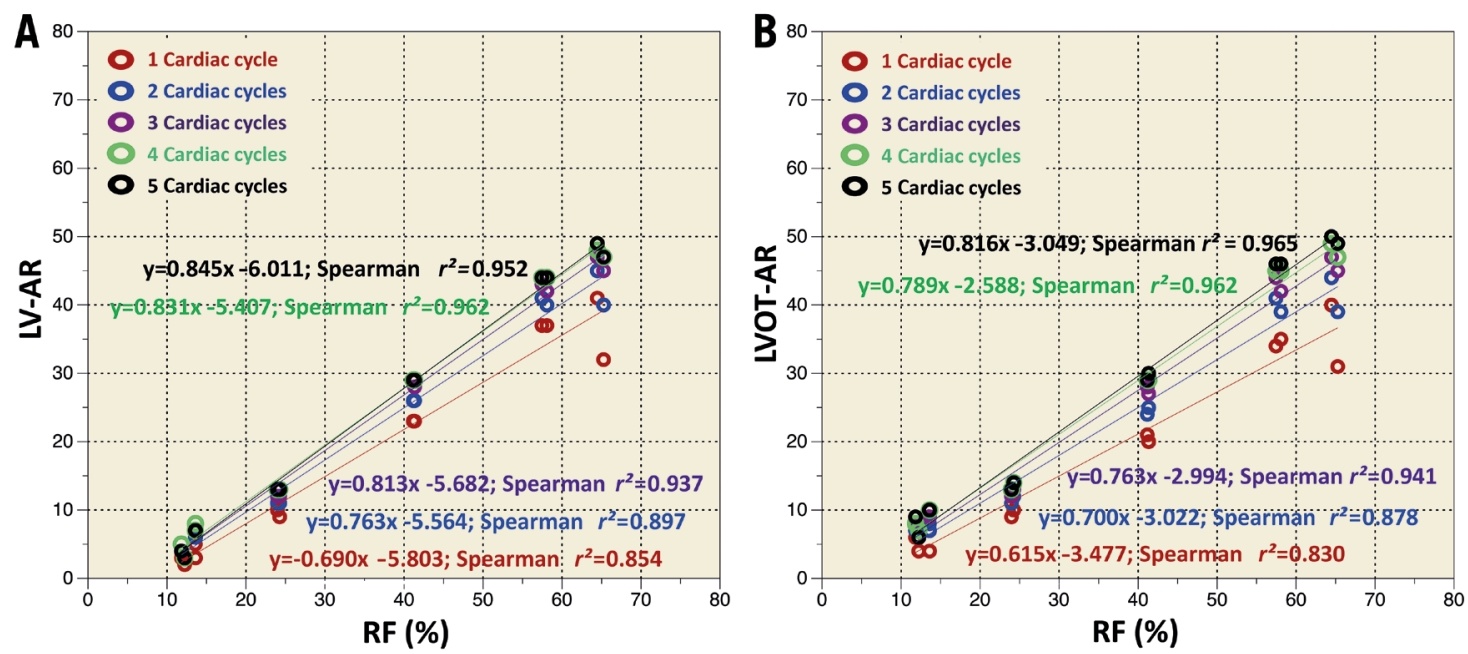

Figure 6. Correlation between LV-AR and LVOT-AR and RF using different numbers of cardiac cycles. Scatter plots with the lines of best fit displaying the correlations of LV-AR and LVOT-AR with RF when one, two, three, four or five cardiac cycle(s) is/are included in the analysis.

analyst. The ICC was 0.999 (95\% CI: 0.998-1.000) for LV-AR and 0.999 (95\% CI: $0.998-1.000)$ for LVOT-AR. The average intra-observer difference was $-0.67 \%$ for $\mathrm{LV}$-AR and $-0.25 \%$ for LVOT-AR, while the $95 \%$ LOA were $\pm 1.27 \%$ and $\pm 1.22 \%$, respectively (Supplementary Figure 1).

\section{Discussion}

Quantitative videodensitometric assessment of AR severity is based on the concept of comparing opacification of the LV to that of the aortic root after aortic root angiography ${ }^{17-19}$. The present study provides an in vitro validation of this concept in a THV module through comparison with the gold standard (actual controlled RF of AR). The strong correlation between videodensitometric parameters and RF further supports the results of previous clinical studies which showed a significant correlation between videodensitometric parameters of PVR severity and clinical outcomes after TAVI ${ }^{8,9,20}$.

In the minimalist TAVI era, the majority of procedures are performed without transoesophageal echocardiographic (TEE) guidance. A combination of transthoracic echocardiography (TTE) and a haemodynamic index (such as the aortic regurgitation index [ARI]) can serve as a substitute for TEE when TAVI is performed without general anaesthesia. However, the frequency of an ARI $<25$ (reported to correspond to significant PVR and to portend a worse prognosis ${ }^{21}$ ) among TAVI patients is very high, ranging from 34 to $57 \%{ }^{21-23}$, and an ARI of $<25$ frequently co-exists with no/trivial AR, particularly in the presence of relative bradycardia ${ }^{22}$. When TTE is technically adequate (in patients with a good acoustic window), it remains subject to limited reproducibility and qualitative and overlapping severity grades ${ }^{5,24,25}$. On the one hand, aortography is a practical tool as it is already a routine part of all procedures and gives a direct assessment of regurgitation severity without any inferences or assumptions. On the other hand, ARI utilises pressures as a surrogate for regurgitation severity and assumes that a rise of LV pressure is the result of PVR, although it might rise due to periprocedural myocardial ischaemia ${ }^{4}$. Doppler echocardiography also utilises mainly colour Doppler measurements at a certain jet level as a surrogate for PVR severity and assumes that this level is the neck of the jet, although the jets are often multiple and multi-level ${ }^{4}$. The limitations of aortography are, however, well acknowledged and are basically related to the subjective qualitative assessment ${ }^{26}$. Videodensitometric technique aims to address these limitations. Notwithstanding this, videodensitometric methods are not without limitations. An overlap of the contrast-filled descending aorta on the LV and/or aortic root is an important technical challenge to videodensitometric analysis ${ }^{4}$. The definition of a patient-specific overlap-free fluoroscopic projection is, however, possible using computed tomographic planning ${ }^{27}$.

\section{VIDEODENSITOMETRIC METHODS: ACCURACY VS. PRACTICALITY}

Although aortographic assessment of AR has long been based on the visual assessment of the extent of opacification of the entire LV as compared to the aortic root (Sellers method), we hypothesised that interrogating only the basal one third of the LV (LVOT-AR) would be adequate. This is based on the fact that any contrast that leaks from the aortic root has to go through the LVOT, but does not necessarily reach the mid and apical segments. This is even more relevant in the setting of PVR, where regurgitation is most commonly paravalvular. Paravalvular leak typically follows an eccentric, wall-impinging course ${ }^{28}$, limiting its free penetration towards the LV apex. Moreover, LVOT-AR has been shown to be less influenced by background radiodensities (e.g., the contrastfilled descending aorta and the diaphragm) and variability of the LV size and function ${ }^{9,10,18}$ than the entire LV interrogation method (LV-AR and qRA). In the present study, the concept of LVOT-AR which was previously shown to correlate with clinical and surrogate endpoints after TAVI ${ }^{8,9}$ is further supported by a good correlation with the RF. 
Overall, the correlation between videodensitometric parameters of PVR severity and RF was very strong. Moreover, the difference between LV-AR and LVOT-AR was very small and clinically irrelevant, implying that both parameters can be used interchangeably. Therefore, in the clinical setting when the LV apex is not within the fluoroscopic view or is overlapped by the diaphragm, by gastric air, or by lung shadow, LVOT-AR is a practical and accurate alternative to LV-AR.

We found that the accuracy of the concept of the RAUC (applied in LV-AR and LVOT-AR) is influenced by the number of cardiac cycles included in the analysis. Averaging the values of the RAUC over four cardiac cycles seems to be the ideal setting, with more than four cycles adding very little to accuracy, yet prolonging the acquisition and exposing the patient and the physician to needless irradiation. Moreover, with too long acquisition in the clinical setting, contamination of the ROI by coronary opacification and myocardial blush becomes more likely. Although less important in older patients, a higher dose of irradiation can be an issue for younger individuals in whom TAVI seems to be a promising option and in whom accurate assessment of PVR is even more crucial. Therefore, an ideal PVR assessment method should not expose the patient to increased irradiation. Reassuringly, a single cine run of three to five cardiac cycles was shown in the present experiment to be sufficient for an accurate videodensitometric analysis.

The importance of the relative max and the maximum upslope is that both parameters are less influenced by the number of cardiac cycles analysed and can thus be calculated from a single cardiac cycle. We found that these two parameters yield their best accuracy when derived from the cardiac cycle in which the contrast density in the aortic root reaches its peak (results not shown). We observed that this takes place in the second cardiac cycle after contrast injection. It turns out that operators are recommended to acquire a fluoroscopic run of at least four cardiac cycles after contrast injection. In cases when this rule is fulfilled but the LV mid or apical third cannot yield a reliable analysis (e.g., overlapped by background structures), LVOT-AR is a good alternative. In case fewer than four cardiac cycles are available for the analysis, maximum upslope can be measured from the second cardiac cycle after contrast injection.

Like other quantitative methods of AR assessment (e.g., magnetic resonance imaging-based and Doppler-based RF), the sum of all regurgitant jets (irrespective of their level/number/mechanism) is represented. Notwithstanding, significant PVR after TAVI is most commonly paravalvular, and visual angiography is unable to differentiate paravalvular from transvalvular regurgitation. However, inability to differentiate paravalvular from transvalvular regurgitation remains a limitation of the videodensitometric assessment, as the mechanism of regurgitation should be confirmed before a corrective measure (e.g., post-dilation) is performed. So, in an ideal scenario, videodensitometric assessment should replace visual assessment as the first post-deployment screening test, followed, in case of significant PVR, by an ad hoc transthoracic echocardiographic confirmation of the regurgitation mechanism.

\section{LIMITATIONS AND ADVANTAGES OF THE MOCK CIRCULATION SYSTEM AND THE PVR MODEL}

The settings of the experiment have taken into account the clinical setting in the cathlab (e.g., physiologic cardiac output and heart rate, catheter type and size, as well as type, volume and rate of contrast injection) and, more importantly, used a model of THV paravalvular regurgitation for testing.

The mock circulation system has a 30 litre container which provides a good dilution of contrast. Therefore, we could ignore the accumulating contrast during the successive experiments. Moreover, the software subtracts background radiodensities present in the field of analysis.

The LV chamber was represented by a rigid cylindrical tube, which obviously lacks the geometry and the physiologic compliance of a human ventricle, but facilitates the measurement of the flow rate which is easier to quantitate in a rigid cylindrical than in a compliant globular chamber ${ }^{13,29}$. An elastic tube was used to substitute the aortic root while exhibiting a physiologiclike distensibility. It is noteworthy that aortic root elasticity was previously reported to be associated with the severity of $\mathrm{AR}^{30}$. However, two important differences between the aortic root tube used in the model and the human aortic root existed: 1) the lack of coronary arteries, and 2) the lack of coronary sinuses. In a clinical setting, coronary artery opacification and myocardial blush are background radiodensities that interfere with videodensitometric assessment of aortograms and might interfere with the accuracy of analysis. This interference is basically seen when analysis involves long fluoroscopic runs (allowing coronary contrast filling and myocardial blush to take place).

The aortic valve closing volume, which contributes together with the regurgitant flow to the reverse flow, is a confounder to the calculation of regurgitation volume and fraction, especially in sinus-less systems ${ }^{15}$. Although the closing volume typically amounts to $\leq 10 \%$ of the stroke volume, this volume can reach up to $25 \%$ of the stroke volume in sinus-less systems ${ }^{15}$. Although we attempted to account for the closing volume and to segregate it from the actual regurgitation volume, the closing volume might still have led to RF overestimation and, hence, to the apparent tendency of the videodensitometric RAUC to give lower absolute values than the RF. Moreover, this "overestimation" might have contributed to the relatively large regurgitation at baseline (RF: 12\%).

Although it is well acknowledged that paravalvular leakage jets have peculiar characteristics that limit extension of the rules of assessment of transvalvular regurgitation ${ }^{4,28}$, dedicated paravalvular leakage models are scarce. To the best of our knowledge, this is the first in vitro model that uses an actual commercially available THV to validate a PVR assessment method. It should be noted, however, that, before creating the artificial paravalvular leakage, an RF of $12 \%$ was recorded and, accordingly, smaller RF than $12 \%$ were not possible to test. This regurgitation measured before THV deformation can be explained by a combination of a transvalvular regurgitation of the clinically discarded THV 
and the "overestimation" effect of the valve closing volume. In the present study, a cobalt-chromium balloon-expandable THV with annular leaflet position was used. Although the reaction of different THV platforms to the screw-induced deformation might vary, the videodensitometric analysis is minimally influenced by these differences. This is because the origin of the paravalvular leak (at the device deformation point) is excluded from the analysis. The regions of interest include the subvalvular segment of the LV (LVOT) and the supravalvular segment of the aortic root. Therefore, the analysis is minimally influenced by the morphology of the regurgitation orifice.

\section{Conclusions}

Quantitative assessment of prosthetic valve regurgitation by videodensitometry of aortograms is very well correlated with the regurgitation fraction. The restriction of the videodensitometric analysis to the subaortic segment can be more suitable for the assessment of PVR compared to the entire LV interrogation, as it is more feasible in the clinical setting and is accurate in the in vitro setting.

\section{Impact on daily practice}

Quantitative assessment of PVR by videodensitometry of aortograms is an accurate and reproducible method that can be used to guide TAVI procedures.

\section{Guest Editor}

This paper was guest edited by William Wijns, MD, PhD; Lambe Institute for Translational Medicine and Curam, National University of Ireland, Galway, and Saolta University Healthcare Group, Galway, Ireland.

\section{Conflict of interest statement}

J-P. Aben is employed by Pie Medical Imaging. M. van Sloun and T. Suchecki are employed by ACIST Medical Systems. The other authors have no conflicts of interest to declare. The Guest Editor has no conflicts of interest to declare.

\section{References}

1. Kodali SK, Williams MR, Smith CR, Svensson LG, Webb JG, Makkar RR, Fontana GP, Dewey TM, Thourani VH, Pichard AD, Fischbein M, Szeto WY, Lim S, Greason KL, Teirstein PS, Malaisrie SC, Douglas PS, Hahn RT, Whisenant B, Zajarias A, Wang D, Akin JJ, Anderson WN, Leon MB; PARTNER Trial Investigators. Two-year outcomes after transcatheter or surgical aortic-valve replacement. $N$ Engl J Med. 2012;366:1686-95.

2. Kodali S, Pibarot P, Douglas PS, Williams M, Xu K, Thourani V, Rihal CS, Zajarias A, Doshi D, Davidson M, Tuzcu EM, Stewart W, Weissman NJ, Svensson L, Greason K, Maniar H, Mack M, Anwaruddin S, Leon MB, Hahn RT. Paravalvular regurgitation after transcatheter aortic valve replacement with the Edwards sapien valve in the PARTNER trial: characterizing patients and impact on outcomes. Eur Heart J. 2015;36:449-56.
3. Athappan G, Patvardhan E, Tuzcu EM, Svensson LG, Lemos PA, Fraccaro C, Tarantini G, Sinning JM, Nickenig G, Capodanno D, Tamburino C, Latib A, Colombo A, Kapadia SR. Incidence, predictors, and outcomes of aortic regurgitation after transcatheter aortic valve replacement: meta-analysis and systematic review of literature. $J$ Am Coll Cardiol. 2013;61:1585-95.

4. Abdelghani M, Soliman OI, Schultz C, Vahanian A, Serruys PW. Adjudicating paravalvular leaks of transcatheter aortic valves: a critical appraisal. Eur Heart J. 2016;37:2627-44.

5. Hahn RT, Pibarot P, Weissman NJ, Rodriguez L, Jaber WA. Assessment of paravalvular aortic regurgitation after transcatheter aortic valve replacement: intra-core laboratory variability. J Am Soc Echocardiogr. 2015;28:415-22.

6. Abdelghani M, Tateishi H, Spitzer E, Tijssen JG, de Winter RJ, Soliman OI, Hahn RT, Serruys PW. Echocardiographic and angiographic assessment of paravalvular regurgitation after TAVI: optimizing inter-technique reproducibility. Eur Heart $J$ Cardiovasc Imaging. 2016;17:852-60.

7. Sellers RD, Levy MJ, Amplatz K, Lillehei CW. Left Retrograde Cardioangiography in Acquired Cardiac Disease: Technic, Indications and Interpretations in 700 Cases. Am J Cardiol. 1964;14:437-47.

8. Abdelghani M, Tateishi H, Miyazaki Y, Cavalcante R, Soliman OI, Tijssen JG, de Winter RJ, Baan J Jr, Onuma Y, Campos CM, Leite RS, Mangione JA, Abizaid A, Lemos PA, de Brito FS Jr, Serruys PW. Angiographic assessment of aortic regurgitation by video-densitometry in the setting of TAVI: Echocardiographic and clinical correlates. Catheter Cardiovasc Interv. 2017; 90:650-9.

9. Tateishi H, Campos CM, Abdelghani M, Leite RS, Mangione JA, Bary L, Soliman OI, Spitzer E, Perin MA, Onuma Y, Serruys PW, Lemos PA, Brito FS Jr. Video densitometric assessment of aortic regurgitation after transcatheter aortic valve implantation: results from the Brazilian TAVI registry. EuroIntervention. 2016;11:1409-18.

10. Schultz CJ, Slots TL, Yong G, Aben JP, Van Mieghem N, Swaans M, Rahhab Z, El Faquir N, van Geuns R, Mast G, Zijlstra F, de Jaegere PP. An objective and reproducible method for quantification of aortic regurgitation after TAVI. EuroIntervention. 2014;10:355-63.

11. Oguri A, Yamamoto M, Mouillet G, Gilard M, Laskar M, Eltchaninoff H, Fajadet J, Iung B, Donzeau-Gouge P, Leprince P, Leguerrier A, Prat A, Lievre M, Chevreul K, Dubois-Rande JL, Chopard R, Van Belle E, Otsuka T, Teiger E; FRANCE 2 Registry Investigators. Clinical outcomes and safety of transfemoral aortic valve implantation under general versus local anesthesia: subanalysis of the French Aortic National CoreValve and Edwards 2 registry. Circ Cardiovasc Interv. 2014;7:602-10.

12. Wiegerinck EM, Boerlage-van Dijk K, Koch KT, Yong ZY, Vis MM, Planken RN, Eberl S, de Mol BA, Piek JJ, Tijssen JG, Baan J Jr. Towards minimally invasiveness: transcatheter aortic valve implantation under local analgesia exclusively. Int J Cardiol. 2014;176:1050-2. 
13. Schampaert S, Pennings KA, van de Molengraft MJ, Pijls NH, van de Vosse FN, Rutten MC. A mock circulation model for cardiovascular device evaluation. Physiol Meas. 2014;35:687-702.

14. Geven MC, Bohte VN, Aarnoudse WH, van den Berg PM, Rutten MC, Pijls NH, van de Vosse FN. A physiologically representative in vitro model of the coronary circulation. Physiol Meas. 2004;25:891-904.

15. Bellhouse BJ, Bellhouse FH. Mechanism of closure of the aortic valve. Nature. 1968;217:86-7.

16. International Organisation for Standardization (ISO). ISO 5840-1:2015. Cardiovascular implants -- Cardiac valve prostheses -- Part 1: General requirements. ISO Copyright Office 2015. https:// www.iso.org/standard/61732.html

17. von Bernuth G, Tsakiris AG, Wood EH. Quantitation of experimental aortic regurgitation by roentgen videodensitometry. Am J Cardiol. 1973;31:265-72.

18. Klein LW, Agarwal JB, Stets G, Rubinstein RI, Weintraub WS, Helfant RH. Videodensitometric quantitation of aortic regurgitation by digital subtraction aortography using a computer-based method analyzing time-density curves. Am J Cardiol. 1986;58:753-6.

19. Grayburn PA, Nissen SE, Elion JL, Evans J, DeMaria AN. Quantitation of aortic regurgitation by computer analysis of digital subtraction angiography. J Am Coll Cardiol. 1987;10:1122-7.

20. Tateishi H, Abdelghani M, Cavalcante R, Miyazaki Y, Campos CM, Collet C, Slots TLB, Leite RS, Mangione JA, Abizaid A, Soliman OI, Spitzer E, Onuma Y, Serruys PW, Lemos PA, de Brito FS Jr. The interaction of de novo and pre-existing aortic regurgitation after TAVI: insights from a new quantitative aortographic technique. EuroIntervention. 2017;13:60-8.

21. Sinning JM, Hammerstingl C, Vasa-Nicotera M, Adenauer V, Lema Cachiguango SJ, Scheer AC, Hausen S, Sedaghat A, Ghanem A, Muller C, Grube E, Nickenig G, Werner N. Aortic regurgitation index defines severity of peri-prosthetic regurgitation and predicts outcome in patients after transcatheter aortic valve implantation. J Am Coll Cardiol. 2012;59:1134-41.

22. Jilaihawi H, Chakravarty T, Shiota T, Rafique A, Harada K, Shibayama K, Doctor N, Kashif M, Nakamura M, Mirocha J, Rami T, Okuyama K, Cheng W, Sadruddin O, Siegel R, Makkar RR. Heartrate adjustment of transcatheter haemodynamics improves the prognostic evaluation of paravalvular regurgitation after transcatheter aortic valve implantation. EuroIntervention. 2015;11:456-64.

23. Vasa-Nicotera M, Sinning JM, Chin D, Lim TK, Spyt T, Jilaihawi H, Grube E, Werner N, Nickenig G, Kovac J. Impact of paravalvular leakage on outcome in patients after transcatheter aortic valve implantation. JACC Cardiovasc Interv. 2012;5:858-65.

24. Orwat S, Diller GP, Kaleschke G, Kerckhoff G, Kempny A, Radke RM, Buerke B, Burg M, Schulke C, Baumgartner H. Aortic regurgitation severity after transcatheter aortic valve implantation is underestimated by echocardiography compared with MRI. Heart. 2014;100:1933-8.

25. Ribeiro HB, Le Ven F, Larose E, Dahou A, NombelaFranco L, Urena M, Allende R, Amat-Santos I, Ricapito Mde L, Thébault C, Clavel MA, Delarochelliére R, Doyle D, Dumont E, Dumesnil JG, Pibarot P, Rodés-Cabau J. Cardiac magnetic resonance versus transthoracic echocardiography for the assessment and quantification of aortic regurgitation in patients undergoing transcatheter aortic valve implantation. Heart. 2014;100:1924-32.

26. Sherif MA, Abdel-Wahab M, Beurich HW, Stocker B, Zachow D, Geist V, Tölg R, Richardt G. Haemodynamic evaluation of aortic regurgitation after transcatheter aortic valve implantation using cardiovascular magnetic resonance. EuroIntervention. 2011; 7:57-63.

27. Teng J, Nijenhuis V, Swaans M, Yong G, Schultz C. How to plan an Overlap Free Projection on CTA or fluoroscopy to facilitate quantitative analysis. EuroIntervention. 2017 Jun 13. [Epub ahead of print].

28. Cape EG, Yoganathan AP, Weyman AE, Levine RA. Adjacent solid boundaries alter the size of regurgitant jets on Doppler color flow maps. J Am Coll Cardiol. 1991;17:1094-102.

29. Bozkurt S, van de Vosse FN, Rutten MC. Enhancement of Arterial Pressure Pulsatility by Controlling Continuous-Flow Left Ventricular Assist Device Flow Rate in Mock Circulatory System. JMed Biol Eng. 2016;36:308-15.

30. Grotenhuis HB, Ottenkamp J, Westenberg JJ, Bax JJ, Kroft LJ, de Roos A. Reduced aortic elasticity and dilatation are associated with aortic regurgitation and left ventricular hypertrophy in nonstenotic bicuspid aortic valve patients. J Am Coll Cardiol. 2007;49:1660-5.

\section{Supplementary data}

Supplementary Figure 1. Reproducibility of LVOT-AR and LV-AR. Moving image 1. Examples of low-grade (left) and high-grade (right) paravalvular regurgitation. For each case, the following are displayed: 1) the angiographic cine run (upper left), 2) the colourcoded contrast density map (upper right), and 3) the time-density curves of the region of interest and of the reference region (lower panel). The relative area under the curve (RAUC) is automatically calculated from the time-density curves.

The supplementary data are published online at: http://www.pcronline.com/ eurointervention/128th_issue/246 


\section{Supplementary data}

Supplementary Figure 1. Reproducibility of LVOT-AR and LV-AR.

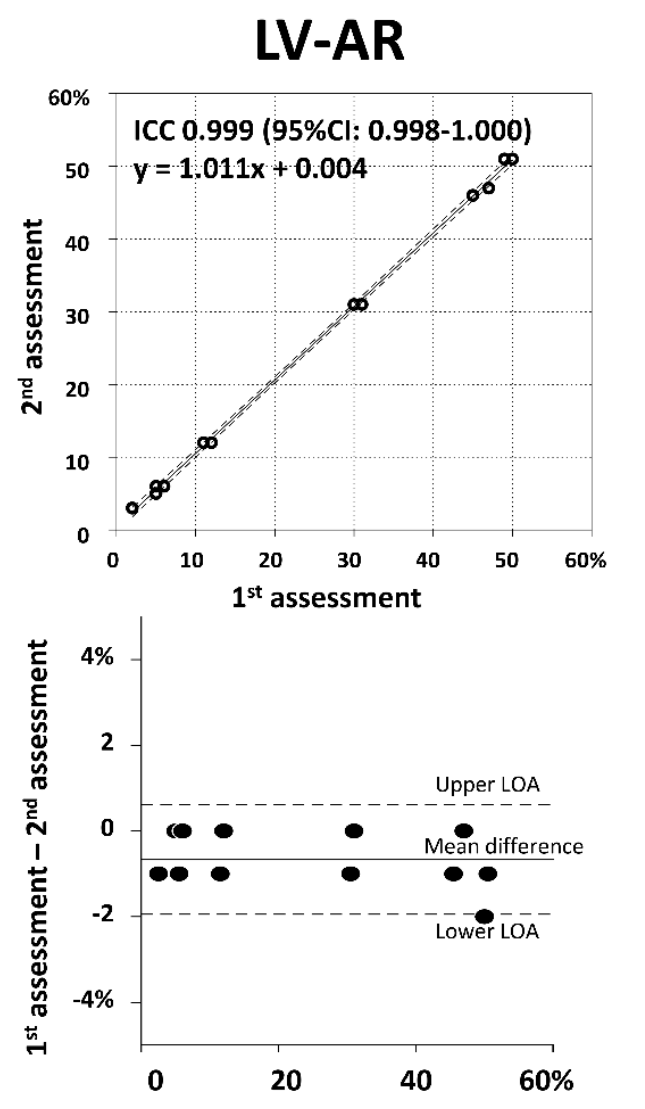

Average of $1^{\text {st }}$ assessment and $2^{\text {nd }}$ assessment
LVOT-AR
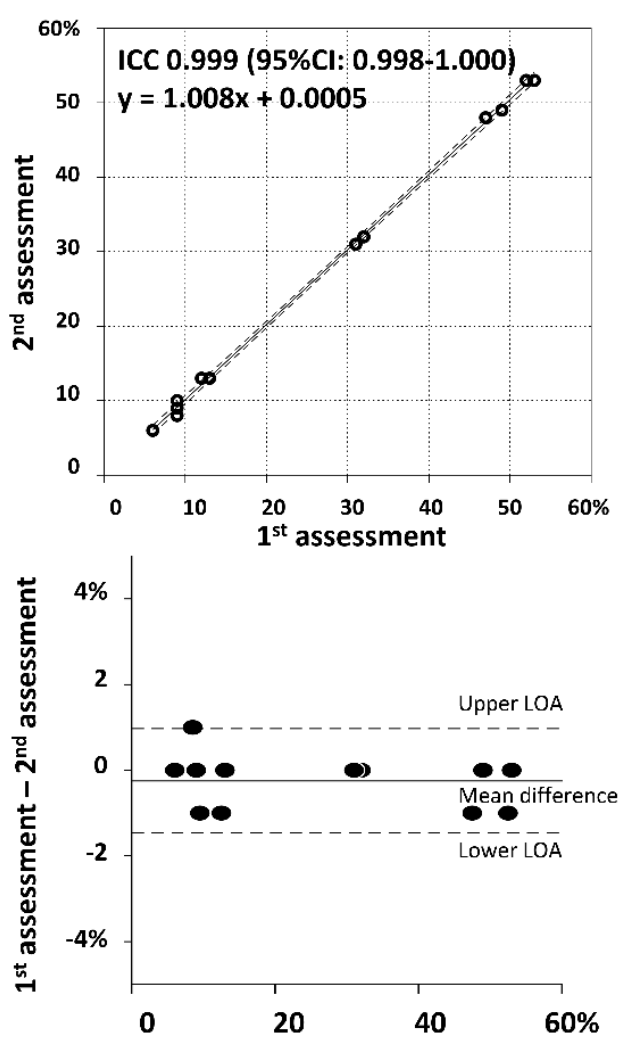

Average of $1^{\text {st }}$ assessment and $2^{\text {nd }}$ assessment

Upper panels: scatter plots displaying intra-observer reproducibility of LV-AR (left) and LVOT-AR (right). Lower panels: intra-observer variability of LV-AR (left) and LVOT-AR (right) displayed on Bland-Altman plots. 